childhood. The present patient is an adult who never gave any history of previous attacks of pain, and consulted a doctor for the first time at the age of 21 years. It seems almost certain that the abnormal lie of the small intestine was due to the sac enclosing it. This sac prevented it from taking its final definitive position. It is difficult to explain the origin of this sac.

The unsolved question is why did this man have symptoms at the age of 21 and not before? With the growth of the patient his intestine also attained the adult size. It is quite possible that the sac did not grow equally fast. If the space inside the sac was inadequate to accommodate intestinal distension after meals, it might account for the colicky pains.

I am grateful to Mr. D. Lincoln Lewis, under whose care the patient was admitted, and to Dr. M. R. E. Dean, who confirmed the diagnosis after the barium meal. The Birmingham Regional Hospital Board helped me financially.

K. P. HARDAS, M.S., F.R.C.S.ED.

Surgical Registrar, Royal Salop Infirmary, Shrewsbury. REFERENCES

Devine, H. B. (1932). British fournal of Surgery, 20, 204.

Devlin, H. B., Williams, R. S. M., and Pierce, J. W. (1968). British Medical fournal, 1, 803.

\section{Nephrotic Syndrome Induced by Gold Therapy}

British Medical fournal, 1970, 2, 772

Gold therapy has been shown to be of value in the treatment of rheumatoid arthritis (Empire Rheumatism Council Research Subcommittee, 1960), though because of occasional dangerous side-effects it is recommended only in cases not responding to simpler measures. A nephrotic syndrome has rarely been reported as a complication of gold therapy and we here describe a further case.

\section{CASE Report}

The patient, a 44-year-old bus conductor, developed seropositive rheumatoid arthritis in the summer of 1966. The first metatarsophalangeal joints were affected initially, and over the next five months the arthritis became generalized. Treatment with indomethacin gave little relief and a course of weekly injections of sodium aurothiomalate was started on 15 December 1966. The dose was gradually increased from 10 to $50 \mathrm{mg}$. over three weeks, and thereafter kept at this level, the urine being examined before each injection. A total dose of $500 \mathrm{mg}$. had been given before therapy was stopped at the end of February 1967, when the patient developed heavy proteinuria (Albustix $300 \mathrm{mg} . / 100 \mathrm{ml}$.). He was then treated with plaquenil for three months. Proteinuria persisted and minimal ankle oedema developed in June. This became more pronounced in July and was beginning to resolve when he was referred to the renal unit in September. At that time his hands showed the classical changes of active rheumatoid arthritis and most of the large joints were also involved. He had slight oedema of both ankles without raised jugular venous pressure or other evidence of heart disease. Blood pressure was $130 / 80$.

Investigation Results.-24-hour urinary protein excretion $3.4 \mathrm{~g}$. Urine microscopy-occasional granular casts. Blood urea 27 mg./100 ml., sodium $142 \mathrm{mEq} / 1$., potassium $4 \mathrm{mEq} / 1$., chloride 98 $\mathrm{mEq} / 1$., $\mathrm{CO}_{2}$ content $26 \mathrm{mEq} / 1$. Serum total protein $6 \cdot 15 \mathrm{~g} . / 100$ $\mathrm{ml}$. (albumin $40 \%$, globulin $60 \%$ ). Serum electrophoresis showed an increase in alpha-2 globulin. Creatinine clearance $114 \mathrm{ml} . / \mathrm{min}$ L.E. cell test negative. Immunofluorescent test for antinuclear factor negative. Modified Rose-Waaler test positive 1/128. Left renal biopsy: the specimen contained 11 glomeruli, one of which was hyalinized, the remainder being histologically normal; the proximal convoluted tubules showed some hyaline droplet change; there was no evidence of damage to the basement membrane. Immunological protein clearances: IgG/siderophilin $=0.25$ (Cameron and Blandford, 1966), alpha-2/siderophilin $=0.016$ (MacLean and Robson, 1967).
His oederra was controlled on treatment with $40 \mathrm{mg}$. of frusemide daily. By February 1968 proteinuria had cleared, plasma proteins returned to normal (total $6.5 \mathrm{~g} . / 100 \mathrm{ml}$. with normal electrophoresis), and diuretic treatment was withdrawn. There has been no recurrence of proteinuria to date.

\section{COMMENT}

The occurrence of nephrotic syndrome in patients with the clinical picture of rheumatoid arthritis is not rare. It may appear if the underlying cause of the arthritis is systemic lupus erythematosus rather than rheumatoid disease, or if renal amyloid develops. Proteinuria may also occur if an arteritis develops as part of the rheumatoid process or, more rarely, granulomatous lesions in the kidney may be the cause of proteinuria (Sørenson, 1966). These conditions are very unlikely to explain this patient's renal lesion since renal biopsy showed normal glomeruli with no evidence of amyloid, the L.E. test was negative, and the antinuclear factor was not detected in the serum. Of course "idiopathic" ("minimal change") nephrotic syndrome may occur coincidentally in patients with rheumatoid arthritis. This is unlikely in our patient's case, since remission began within three months without steroid therapy, and spontaneous remission from idiopathic nephrotic syndrome in adults is uncommon in the first year (Medical Research Council, 1970).

The mechanism by which gold induces renal damage in man is not known. Sørenson (1966) reviewed the clinical and experimental work on the effect of gold on the kidney and summarized the present state of knowledge. After the injection of gold salts in man and experimental animals gold can be detected in the epithelium of the proximal convoluted tubulc in the early months and later in the glomeruli, distal tubular epithelium, and interstitium. These deposits do not usually interfere with renal function. Large doses of gold salt (3.5$4.5 \mathrm{~g}$. total) often cause proteinuria, presumably due to direct metal poisoning. With smaller doses the comparative rarity of renal complications and lack of relationship to dose within the therapeutic range (Handlova, 1968) are more suggestive of a hypersensitivity reaction (van den Broek and Maung, 1966).

Renal biopsy has of course been available only in the more recently reported cases. Van den Broek and Maung (1966) reported a normal appearance of the kidney on light microscopy three months after withdrawal of gold while proteinuria persisted. In our patient the only histological abnormality was hyaline droplet change in the proximal convoluted tubule. This may occur in proteinuria from any cause, and we feel it cannot be attributed to the toxic effect of gold, though it did correspond to the site in which gold is usually found after injection.

This case again emphasizes the importance of routine urine examination before each injection of a gold salt. Handlova (1968) found that $17 \%$ of patients receiving gold therapy developed proteinuria, and this was reversible in most cases.

We would like to thank Professor D. N. S. Kerr and Dr. M. Thompson for permission to report this case.

$$
\begin{aligned}
& \text { R. WILKINSON, M.B., B.SC., M.R.C.P., } \\
& \text { Lecturer in Medicine. } \\
& \text { D. W. ECCLESTON, M.B., B.S., } \\
& \text { Medical Registrar. }
\end{aligned}
$$

Department of Medicine, University of Newcastle upon Tyne and Royal Victoria Infirmary, Newcastle upon Tyne NE1 4LP.

$$
\text { REFERENCES }
$$

Cameron, J. S., and Blandford, G. (1966). Lancet, 2, 242.

Empire Rheumatism Council Research Subcommittec (1960). Annals of

the Rheumatic Diseases, 19, 95.
Handlova, D. (1968). Vnitŕni Lékarstvi, 14. 115.

MacLean, P. R., and Robson, J. S. (1967). Lancet, 1, 539.

Medical Res arch Council (1970). Report of the Subcommittee on Steroid Therapy of Nephrotic Syndrome in Adults. To be published.

Sorensen, A. W. S. (1966). The Kidney in Rheumatoid Arthritis, p. 91. Copenhagen, Munksgaard.

Van den Broek, H., and Maung, T. H. (1966). New England fournal of Medicine, 274, 210. 